\title{
Multi-criteria decision model for the selection and location of temporary shelters in disaster management
}

\author{
Manuela Marques Lalane Nappi ${ }^{i^{*}}$ D, Vanessa Nappi ${ }^{2}$ and João Carlos Souza ${ }^{1}$
}

\begin{abstract}
The occurrence of natural or anthropic disasters in Brazil and the world emphasizes the importance of humanitarian logistics. Scholars and practitioners have developed modeling approaches to support aid delivery planning, but little attention has been given to the selection of community or collective temporary shelters. Therefore, this paper proposes a novel multi-criteria decision model focused on the principles of humanitarian logistics for the selection and spatial location of community or collective temporary shelters. This model not only incorporates evaluation criteria from documents published by humanitarian aid organizations and related literature but also the expertise of 23 experienced humanitarian logisticians from the Brazilian Civil Defense. The results quantify the importance of each criterion and enable the development of a decision tool, the ShelterPro software, that can be used to support the decision-making process of selecting temporary shelters. The results also indicate that safety of the facility, cultural adequacy, and location accessibility are the most valuable criteria. With these insights and the decision supporting tool, better humanitarian decisions can be made by humanitarian logistics managers, local authorities, or designated officials in the selection and location of temporary shelters in emergency response.
\end{abstract}

Keywords: Disaster management, Temporary shelters, Performance measurement system, Performance indicators, Multi-criteria decision model

\section{Introduction}

Recent natural and human-made disasters have highlighted the importance of humanitarian logistics in emergency response. In this context, researchers and practitioners have developed modeling approaches to support and improve aid delivery to the population at risk. In general, the research explores analytical models focusing on lessons learned and conceptual boundaries of operational and rescue issues for the humanitarian supply chain (Gralla et al. 2014). These modeling approaches help humanitarian organizations refine their planning and management of storage and distribution strategies to maintain aid during and after the crisis (Apte 2009).

In emergency situations, the selection and location of collective temporary shelters is a fundamental task,

\footnotetext{
*Correspondence: lalppi.ms@gmail.com

${ }^{1}$ Universidade Federal de Santa Catarina (UFSC), Campus Universitário Reitor João David Ferreira Lima - Trindade, Florianópolis, SC 88040-900, Brazil Full list of author information is available at the end of the article
}

alongside the pre-disposition of goods and supplies and the analysis of evacuation processes of the affected population (Apte 2009). In this sense, the selection and location of collective temporary shelters is a decisive factor in the response to disasters, especially to alleviate human suffering. Therefore, humanitarian aid organizations must begin planning processes before the disaster strikes, even though it is difficult to specify when temporary shelters will be needed (Nappi and Souza 2014).

A collective or community temporary shelter is defined as a place where temporary roof, food, clothing, drinking water, health, and protection is provided to a large group of displaced people for a short period (UNICEF 2008). Existing facilities, such as schools, multi-sports gyms, public buildings, among others, can function as temporary shelters for emergency situations if given the necessary resources. Hence, the temporary shelter is the accommodation provided during the 
period between a disaster and the achievement of a long-term shelter solution (Marino et al. 2016).

For the last 5 years, the number of papers addressing the minimum standards for temporary shelters is increasing significantly (Hosseini et al. 2016; Marino et al. 2016; Trivedi and Singh 2017). A substantial part of the literature investigates issues related to social vulnerability but overlooks a more comprehensive perspective on evaluation criteria for collective temporary shelters (Kar and Hodgson 2008; Marino et al. 2016). Furthermore, there has been little research focused on guidelines and systematic approaches to support the decision process of selecting and locating collective temporary shelters (Nappi and Souza 2014; Trivedi and Singh 2017).

Therefore, this study aims to propose a novel multicriteria decision model based on relevant criteria for the selection and location of temporary shelters to support humanitarian logistics managers, local authorities, or designated officials in the decision-making process. The major challenges addressed in this paper are related to the lack of comprehensive criteria to evaluate temporary shelters, and the deficiency of systematic approaches that support humanitarian decision-makers in the selection and location analysis of temporary shelters.

The remainder of this paper is organized as follows. To begin, the theoretical backgrounds related to temporary shelters and multi-criteria models are introduced. Following which, the paper presents the research method used to propose the multi-criteria decision model. The results are then presented and discussed in terms of the defined criteria and their arrangement based on the experts' preferences, its systematization into the model and the supporting decision tool ShelterPro. Finally, the paper consolidates the findings that lead to conclusions and contributions for humanitarian logistics managers and researchers.

\section{Collective temporary shelters}

After a disaster strikes, the immediate focus is on locating victims, providing water, food, medical care, and shelter to survivors. In this context, one of the main purposes of humanitarian logistics lies in the provision of temporary shelters to the population at risk (Apte 2009). The right to housing and shelter is recognized in the Universal Declaration of Human Rights, and other documents produced by multilateral organizations such as the UN (UN General Assembly 1948).

Access to adequate housing and shelter is an essential human need. To fulfill this essential need, the architectural design of temporary shelter solutions must meet specific requirements. These requirements are related not only to technical attributes but also cultural needs of the people affected. The physical design of spaces, including temporary shelters, represents a spatial language, and it may acquire several meanings in the distinct cultural interpretation of individuals (Apte 2009).

Costa et al. (2017) argue that the wide range of requirements to be considered in the selection of emergency shelters is one of the most significant challenges for humanitarian aid planning. However, according to Rolnik (2011), the existing disaster guidelines have not given the necessary attention to the right of adequate housing and shelter. For example, specific requirements such as cultural adequacy and universal accessibility have been addressed only in generic terms (Rolnik 2011; Argüello-Rodríguez 2004).

According to Nappi and Souza (2015), the lack of criteria to support the planning and implementation of temporary shelters can lead to unpredictable factors that could jeopardize the logistics operation as a whole. The authors also affirm that decisions of planning temporary shelters are commonly made after the occurrence of a catastrophic event. In such cases, the available time tends to be insufficient for the consideration of essential criteria that should govern the selection and establishment of temporary shelters (Omidvar et al. 2013).

Academic and technical literature related to the requirements for assessing the performance of collective temporary shelters typically focus on social vulnerability and minimum spatial standards (Hosseini et al. 2016; Marino et al. 2016; Trivedi and Singh 2017). Despite the importance and relevance of this literature, there is a research gap of formal studies specifying criteria or evaluating temporary shelters (Kar and Hodgson 2008).

The most comprehensive document found in the literature about minimum housing requirements in postdisaster situations is the Sphere Handbook, developed under the Sphere Project (2011). This project was initiated in 1997 by a group of non-governmental organizations and the International Red Cross and the Red Crescent Movement. The purpose was to develop a set of universal minimum standards in the field of humanitarian response. This set of minimum standards address critical issues related to the right to adequate housing and shelter and contributes to its progressive implementation. It expresses the shared convictions and commitments of humanitarian organizations. Since its publication, the Sphere Handbook has become a reference for the management of temporary shelters. According to SEDEC/RJ (2006), more than 80 countries adopt their guidelines and indicators for the implementation and management of temporary shelters.

\section{Multi-criteria models in humanitarian logistics}

Multi-criteria decision models are used to help people make decisions according to their preferences by finding the best choices among the possible decision alternatives 
in cases where there are multiple evaluation criteria (Subramoniam et al. 2013). In this way, these models integrate objective measurements with value judgments from experts in order to make the subjectivity of decision-making more explicit (Pavan et al. 2009). Across the literature, multi-criteria modeling approaches have proven to be effective in disaster management when addressing decision problems that require a comprehensive perspective (Gralla et al. 2014; Nappi and Souza 2015).

A key challenge in the development of multi-criteria modeling approaches is the definition of the criteria to be considered and measured in the model (Pavan et al. 2009). Most models apply a collection of performance indicators to function as the basis to operationalize and coordinate the criteria (Poister 2003). In such cases, indicators are measurable values that demonstrate how effectively a phenomenon is performing toward an objective. Also referred to as measures, indicators can be either quantitative or qualitative. Both types are equally important to the decision-making process and multi-criteria models (Beamon 2008).

In general, multi-criteria approaches found in the literature address accessibility of shelters for vulnerable populations, provision of supplies, and planning of infrastructure networks, among other topics in the disaster response context (Hosseini et al. 2016; Trivedi and Singh 2017). The most recurrent research method in the humanitarian aid delivery field is the case study (Marino et al. 2016; Wang 2016; Marshall et al. 2017). In this context, the proposition of multi-criteria models typically applies the analytical hierarchy process (AHP) method (Hosseini et al. 2016; Trivedi and Singh 2017).

The AHP method can be especially useful to build a systemic and consistent evaluation model integrating qualitative and quantitative criteria (Chou et al. 2008). Power (2000) defines AHP as "an approach for the decision-making process that involves structuring multi-criteria models in a hierarchy." The AHP is based on the decomposition of global criteria into local criteria, which in turn, are composed by a set of performance indicators. This method also allows the assessment and assignment of relative importance between the criteria (Saaty 1991).

To assign the relative importance between the criteria, the central idea of hierarchical analysis theory is to reduce the study of systems into a sequence of comparisons in pairs (Saaty 1991). This pairwise comparison is a well-established practice in the development of multicriteria models to determine the importance of each criterion based on the preferences of the stakeholders (Hosseini et al. 2016). This method employs a comparison scale based on verbal assessments ranging from equal to absolute dominance of one element over the other (equal, weak, strong, very strong, absolute) and their corresponding numerical judgments $(1,3,5,7,9)$.
According to Subramoniam et al. (2013), the scale helps stakeholders in the prioritization of intangible criteria. It is particularly relevant in the decision-making process, minimizing possible failures of the model (Saaty 1990).

The critical factor in applying this AHP method resides in obtaining the preferences of multiple stakeholders, such as those receiving the aid, the beneficiaries (Gralla et al. 2014). However, soliciting preferences from beneficiaries might be an impractical and particularly complex task in the midst of an emergency. In addition, shelter assessment may even present low priority when compared to other needs and aid delivery. Experienced humanitarian workers, on the other hand, often understand beneficiaries' preferences and probably will be better equipped to assess several aspects of aid distribution. One example is that beneficiaries may not realize the value of adequate sanitation in the prevention of diseases. The experiences of experts in diverse emergency situations and, as a result, their preferences can better translate the needs of future emergencies. Obtaining the experts' preferences is the most direct and robust route to quantify the importance of criteria in the context of humanitarian aid (Gralla et al. 2014; Hosseini et al. 2016).

Ultimately, multi-criteria modeling approaches combine each indicator measurement with its assigned importance (weight), aggregating according to the hierarchy established in order to obtain a global value for each contemplated alternative decision (Subramoniam et al. 2013). This systematization enables the comparison and prioritization among possible alternatives and supports stakeholders to be better equipped in the decision-making process (Nappi and Souza 2015).

\section{Research method}

This study aims at proposing a novel multi-criteria decision model based on relevant criteria for the selection and location of temporary shelters to support humanitarian logistics managers, local authorities, or designated officials in the decision-making process. To this end, the study begins with the definition of primary evaluation elements that will compose the criteria using a systematic literature review and culminates in the development of the multi-criteria decision model. This research performs five methodological steps, as illustrated in Fig. 1, based on previous research and local characteristics of the present study (Hosseini et al. 2016).

i. Definition of the primary evaluation elements for the criteria: the primary elements to compose the criteria for the model were retrieved from a systematic literature review on temporary community or collective shelters for emergencies. The literature review was carried out using the 


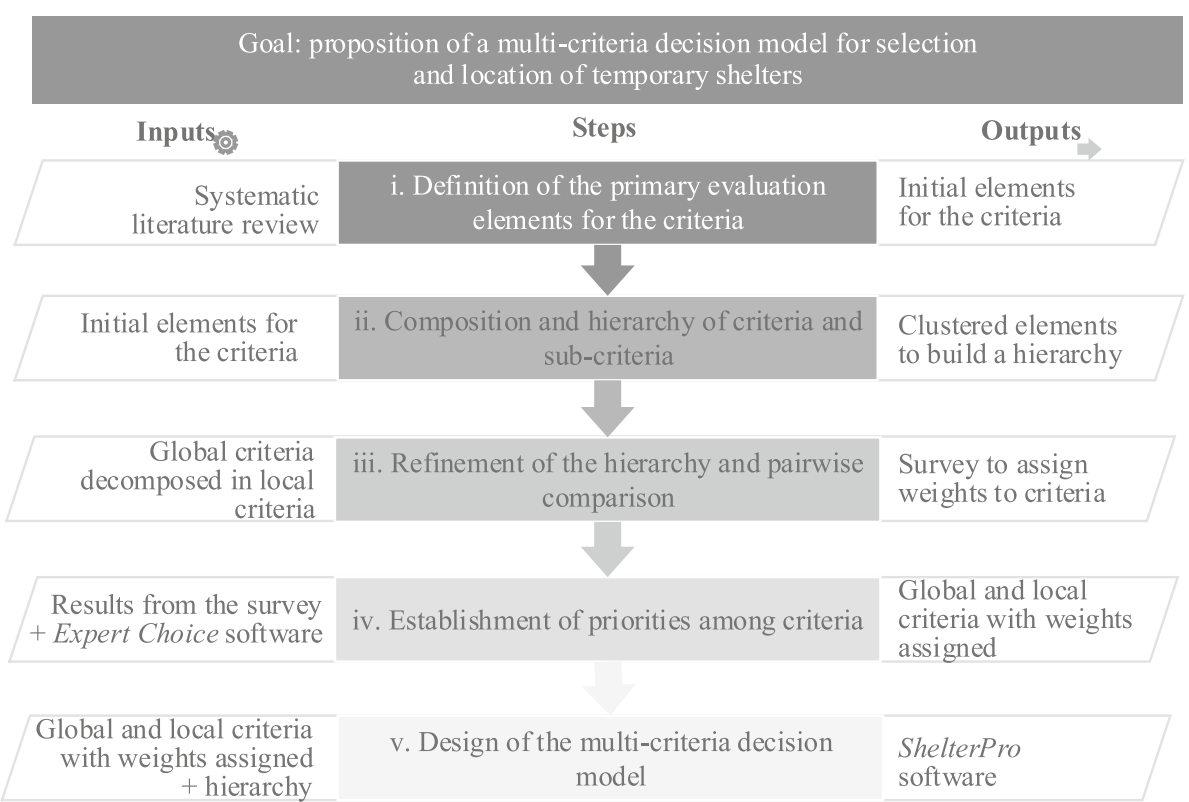

Fig. 1 Methodological steps to develop the multi-criteria decision model ShelterPro

CAPES portal, with access to major electronic databases (Web of Science, Scopus, SciELO, and more). The review included papers from peerreviewed journals and conferences, in addition to books and technical standards from international sources. The search contained the following keywords combined in pairs: "emergency shelters" and "humanitarian logistic"; "emergency shelters" and "disasters"; "emergency shelters" and "evacuation"; "emergency shelters" and "attributes"; "humanitarian logistic" and "performance measures"; "humanitarian logistic" and "multicriteria model." This search was performed in electronic databases without period restriction. These primary elements referred to both technical requirements of temporary shelters and social/ cultural needs of the populations at risk articulated in the reviewed literature.

ii. Composition and hierarchy of criteria and subcriteria: the primary evaluation elements from the previous step were systematically collected and arranged into hierarchies, from the top (general goal) to the last level (specific indicators), as prescribed by the AHP method. This composition was initiated in this step and completed in step iii, described next. The global criteria were created by clustering similar requirements identified in the previous step into categories and making a distinction between quantitative and qualitative measures. At this point, logistics experts with experience in the field of humanitarian aid were invited to complete surveys to indicate which criteria they considered necessary. Only the criteria achieving a specific level of agreement among the experts were maintained. The level of agreement between participants was calculated by dividing the number of times the experts agreed by the total number of evaluations, as recommended by Matos (2014). A minimum of 70\% was used as a threshold to demonstrate a consensus among judges (cf. Stemler 2004). In total, 23 experts from the Santa Catarina Civil Defense (Brazil) participated in this step.

iii. Refinement of the hierarchy and pairwise comparison: each global criterion defined and assessed in the previous step was decomposed by the researchers into local criteria, which were formed by performance indicators. This hierarchy was then refined based on the assessment and feedback given by a group of 12 experts from the Santa Catarina Civil Defense (Brazil). They completed surveys to assess global and local criteria and compare them pairwise (within their own level-global or local). This is the AHP method procedure adopted and recommended across the literature (see discussion on "Multi-criteria models in humanitarian logistics" section). By evaluating pairwise, these experts assessed the importance of 
each criterion against one other, which enabled the calculation of their relative importance. Here, the experts involved were civil defense regional coordinators, operations and assistance manager of the disaster response board, civil defense manager of reestablishment and rehabilitation, civil defense manager of logistics and mobilization, civil defense director of disaster response, technical advisor in the special projects and civil defense reconstruction unit, commander of the fire brigade training center, and manager of civil defense training and research.

iv. Establishment of priorities among criteria: once the experts' consultation was complete, the judgments were inserted into matrices of pairwise comparisons. For each matrix, the weight of the criteria was determined by calculating the priority vector. To calculate these vectors, the researchers used the mathematical software Expert Choice. In addition, the inconsistency index was calculated to allow the identification of discrepancies in the participants' judgments for each matrix. Expert Choice already suggests that the logical measure of inconsistency should be less than 0.1 . This software applies two approaches for the synthesis of the weights: ideal and distributive mode. The ideal mode is indicated for choosing only the best alternative in a given decision situation, whereas the distributive mode is used when one wants to prioritize distinct alternatives (Avila Mogollon 2000). Because the selection and location of temporary shelter may use more than one facility (alternative) to accommodate the entire population at risk, the latter approach seemed more appropriate to this study.

v. Design of the multi-criteria decision model: after establishing the weights of each criterion and evaluating the overall inconsistency of the hierarchy, the multi-criteria decision model was developed. The model is represented by the elements retrieved from the literature in step (i), then clustered into global criteria in step (ii), further refined and decomposed into local criteria in step (iii), and assessed with weights assigned by experts from the civil defense of Santa Catarina state/Brazil in step (iv). These constructs were used to build the functionalities of the software ShelterPro developed in this research. This software uses an algorithm to apply the criteria in order to provide a ranking of temporary shelters. As mentioned before, the tool aims to support knowledgeable workers such as humanitarian logistics managers, local authorities, or designated officials from the civil defense. In addition, the software also enables the creation of distinct local databases of temporary shelters, which is currently composed of examples of temporary shelters from Santa Catarina as a proof of concept. A more detailed description and discussion on the model and tool are presented next.

\section{Results and discussion}

This section presents the results and the related discussion in terms of the definition of the criteria to assess temporary shelters, the definition of the hierarchy and establishment of the weights via experts' consultation, and the design of the multi-criteria model.

\section{Definition of the criteria}

The initial results of this study comprehend the definition of the primary evaluation elements used to compose the criteria. The documents that contributed the most to the definition of the criteria were the Sphere Manual (Sphere Project 2011) and the Temporary Shelter Administration Manual (SEDEC/RJ 2006). In total, nine global criteria were defined, ranging from "Safety" to "Location." Fig. 2 presents an overview of all global and local criteria in a hierarchical tree format for better visualization.

1. Safety: temporary shelters must provide safety, protection, and promote the well-being of the sheltered people. In this sense, public buildings with the potential to function as temporary shelters are often repaired in order to endure disasters and ensure the safety of all. These facilities must be located at a safe distance from the danger zone so that the existing risks are kept to a minimum. Safety concerns should also consider the safety planning of internal routes within the facility. Furthermore, the shelter must reserve an area dedicated to the safe storage of supplies as well as a space for the pets belonging to the affected population.

2. Urban infrastructure: the facility to be used as a temporary shelter must be located where there is an urban infrastructure in place. The facility must be equipped with not only a sewage system (or another type of treatment) but also a waste collection system. Moreover, it should have access to energy and water supply or easy access for heavy vehicles and tankers (for water delivery).

3. Physical adequacy: the sheltered users should be presented with appropriate enclosed spaces 
respecting minimum standard areas. At the same time, these spaces must provide protection from the weather and enable the performance of essential domestic activities and support livelihoods. Physical storage spaces should also be reserved to stock movable items of the affected population salvaged from their households.

4. Cultural adequacy: the facilities should promote design solutions which apply construction materials known to the displaced population. Whenever possible, these choices should not only be culturally and socially accepted but also environmentally sustainable. Therefore, the construction or adaptation of the facilities should be assigned to professionals with local experience.

5. Privacy: the establishment of shelters should consider existing local practices related to privacy and the use of spaces. In this sense, the provision of materials used to separate personal and family spaces can assist in ensuring the privacy of individuals, genders, and between different families.

6. Environmental comfort: shelters should offer thermal and acoustic comfort. Thus, shelters should be positioned in a way that optimizes natural ventilation and sun exposure considering the weather and seasonal factors of the region. Also, the facilities should consider preserving trees and other vegetation in the immediate surroundings of the building.

7. Universal accessibility: temporary shelters must comply with building standards and procedures that apply to the construction industry. This includes accessibility requirements for people with mobility, vision, or communication impairments. Most buildings used as temporary shelters require adaptations or improvements such as the installation of access ramps for people with reduced mobility.

8. Economic aspects: the renovation or construction of shelters should be undertaken in consultation with the competent authorities to articulate a consensual strategy to provide services and maintenance at affordable costs. Furthermore, disaster management strategies should also enable the affected population to gradually improve their situation and move from a temporary shelter to a more permanent housing solution. In this way, the location of the facility plays a vital role in providing access routes to workplaces and other means of subsistence for the affected population.

9. Location: the facility's location should provide safe access to schools, markets, recreational centers, worship places, health clinics and hospitals, as well as other services necessary for the development of daily activities. To that end, the maximum distance (proximity) to be covered by the population at risk to reach the shelter should be considered. Journeys must be planned to be as quick and accurate as possible to enable evacuation plans in cases of emergency. In addition, access and distribution routes for humanitarian aid supplies should also be planned and analyzed in order to optimize times of arrival.

\section{Definition of the hierarchy and establishment of priorities} Using the results of the literature review, the criteria were systematized according to the research method in the following hierarchy. The nine global criteria presented correspond to the high-level categories used to organize the local criteria and measures. Local criteria, in turn, refer to the distinct sub-criteria which compose the global criteria. The performance measures are the quantitative and qualitative metrics retrieved from relevant literature to be considered in each local criterion.

With the definition of these criteria in hand, the weights of the criteria and indicators were evaluated and assigned by a group of 23 experts from Santa Catarina applying the AHP method (Saaty 1990). The diversity and experience of these experts provided the necessary perspective to justify the weights assigned in the same way as previous well-established research (Gralla et al. 2014). In this sense, the weights characterize the preferences of the knowledgeable assessment of these local experts.

Table 1 exemplifies the weights of two global criteria, "Privacy" and "Location," their local criteria and performance indicators. It also portrays the qualitative indicators represented by "yes" or "no," whereas the quantitative criteria are expressed by the word "value." Note that the "Location" criterion is articulated by the term "Map," as it needs the geographical address of the temporary shelter to be evaluated.

The global criterion "Privacy" presents a 10.10\% weight, which was determined by the pairwise comparison of all nine global criteria. The same procedure was adopted for each local criterion; thus, a $6.60 \%$ weight was assigned to "of Families" local criterion. In contrast, the indicators were not judged using a pairwise comparison format (only for global and local criteria). Instead, their weights were assigned using an equal distribution of the local criterion weight to which they belong. In the example, each indicator was assigned to a weight of $2.20 \%$ (i.e., $6.60 \%$ divided by three-the number of indicators within that local criterion).

The full extent of the global and local criteria with their indicators and corresponding weights are presented 
Table 1 Examples of the "Privacy" and "Location" global criteria with weights (wglobal: global weight, wlocal: local weight)

\begin{tabular}{|c|c|c|c|}
\hline \multirow[t]{2}{*}{ Description } & \multicolumn{3}{|c|}{ Weight (w) } \\
\hline & $W_{\text {global }}$ & & $W_{\text {local }}$ \\
\hline Privacy & $10.10 \%$ & & \\
\hline of Families & & & $6.60 \%$ \\
\hline $\begin{array}{l}\text { Indicator 1: the building should ensure privacy and dignity to the people affected, } \\
\text { even if it needs adaptations of the internal space. }\end{array}$ & Yes & No & $2.20 \%$ \\
\hline $\begin{array}{l}\text { Indicator 2: the temporary shelter must have spatial division designed to preserve } \\
\text { family cohesion. }\end{array}$ & Yes & No & $2.20 \%$ \\
\hline $\begin{array}{l}\text { Indicator 3: the temporary shelter must have a number of subdivisions (dormitories) } \\
\text { compatible with the number of sheltered families. }\end{array}$ & Value & & $2.20 \%$ \\
\hline Location & $13.00 \%$ & & \\
\hline Optimal distribution & & & $6.20 \%$ \\
\hline $\begin{array}{l}\text { Indicator 1: maximum distance to be covered by the population at risk to the building } \\
\text { (inform the position on the map). }\end{array}$ & Map & & $2.07 \%$ \\
\hline $\begin{array}{l}\text { Indicator 2: the selection of the facility should consider the maximum time of arrival of } \\
\text { humanitarian aid supplies to the building. }\end{array}$ & Yes & No & $2.07 \%$ \\
\hline Indicator 3: the access routes for the population at risk should be pre-determined. & Yes & No & $2.07 \%$ \\
\hline
\end{tabular}

in the Appendix (Table 2) due to its considerable size (60 indicators).

All the weights assigned are presented in Fig. 3, which displays the final global and local criteria hierarchy. When comparing the initial hierarchical tree (Fig. 2) and the final one (Fig. 3), note that some local criteria were removed. The reason for this was the lack of agreement among experts about their importance. That is, these local criteria did not reach the minimum agreement level $(70 \%)$ in the experts' assessment regarding their role in the selection and location of temporary community or collective shelters in emergencies (see "Research method" section).

Another visualization of the final weights of the local criteria applies the distributive mode, which is suitable for decision situations aiming to rank alternatives. In this prioritization shown in Fig. 4, the weight of each local criterion is multiplied by the weight assigned to the global criterion to which they belong. For the local criteria "Safety of people," the global weight of $20.20 \%$ is multiplied by the local weight of $52.40 \%$ (see Fig. 3), resulting in $10.60 \%$ (see Fig. 4 ). Thus, the weights of the elements of one level were determined according to their importance to the higher level, which allows the establishment of the relative strength of each local criterion in relation to the research goal. The formulation of these weights using this distribution mode has been demonstrated to be consistent and representative since the inconsistency index calculated for the experts' responses achieved a value of 0.02 , meeting the condition of less than 0.1 suggested by the software Expert Choice.
Furthermore, the results shown in Fig. 4 shed some light on the most valuable criteria according to the experts. The top criterion is "Safety of people" characterized by qualitative indicators assessing the protection against further disasters and weather perils, and the safety of different age groups, especially women, children, and the elderly (see Appendix). The second local criterion in terms of importance is "Cultural adequacy of the physical structure." It addresses the fact that the construction or physical adaptation of the temporary shelter should have been assigned to professionals with expertise in local solutions. The third most important criterion is the "Location accessibility" that refers to the qualitative indicator that the location of the building should provide safe access to schools, markets, and other services necessary for the day-to-day lives of the affected population.

It is interesting to notice that the "Location optimal distribution" criterion which refers to the proximity of the shelter and location of the dislodged population (designed as the radius affected by the disaster) is the fifth most important one according to the experts' assessment. This evaluation demonstrates that the priority given to the safety of the displaced population against other disasters is higher than the proximity criterion (referred to as "Location optimal distribution"). This observation is in line with the fact that the most recurrent disaster in Brazil are floods and landslides (GFDRR 2014), which entails that the shortest proximity should not present the highest priority nor be the only criterion to be considered. Therefore, this observation 


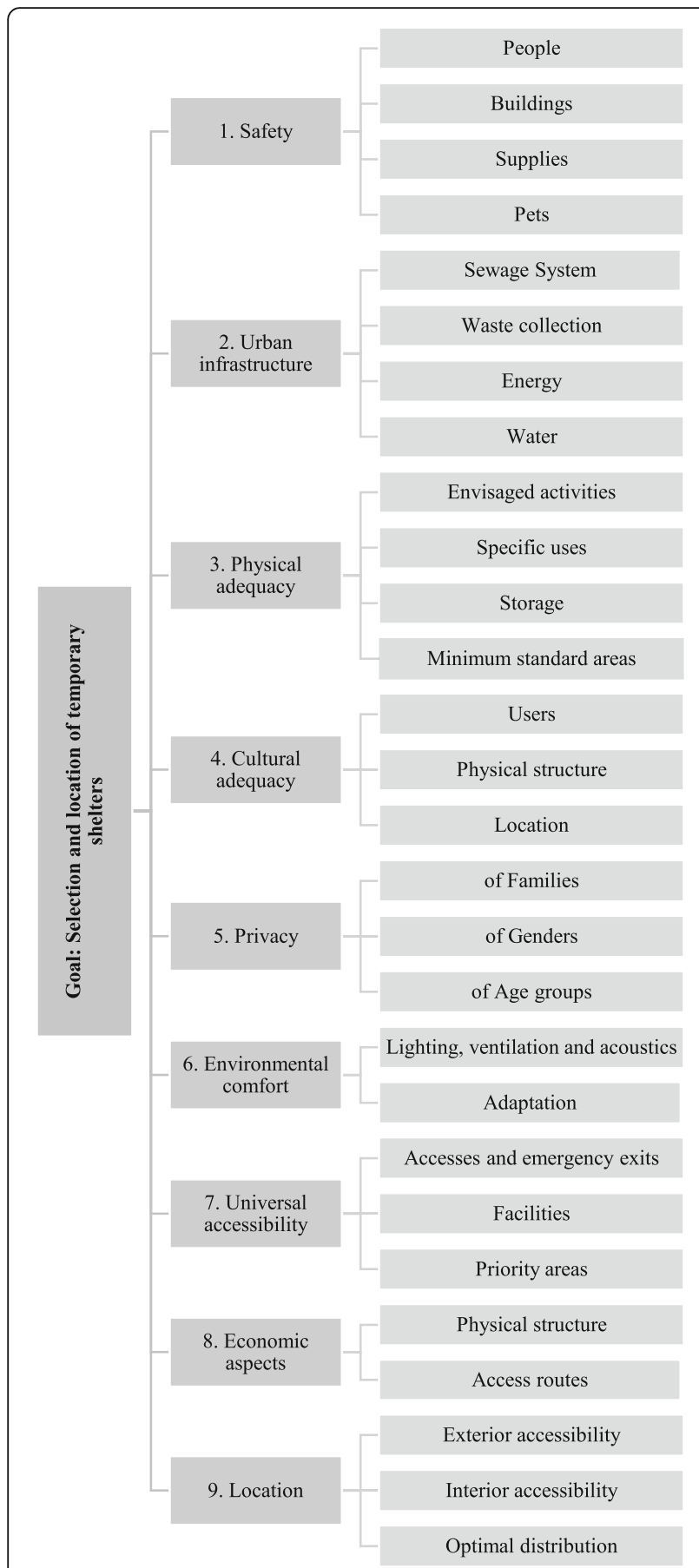

Fig. 2. Initial hierarchical tree representation showing the global and local criteria

reinforces that the decision of selecting and locating shelters should encompass a set of criteria, which is

\footnotetext{
${ }^{1}$ The ShelterPro software was developed in collaboration with the Automation Engineer Raphael Santos da Cunha
}

precisely the proposition of the multi-criteria decision model.

\section{Design of the multi-criteria model}

The ShelterPro ${ }^{1}$ software is built around the multi-criteria model composed by the 24 local criteria and the corresponding 60 indicators. The software was developed using Java programming language. Java has been chosen as it is a simple, robust, and portable programming language. Therefore, the software works independently of platform or operating system, with no compatibility issues among operating systems such as Windows, Mac OS, Linux, etc. A further advantage is that Java is one of the most popular programming languages in use for software development, guaranteeing low-cost maintenance, support, and easy integration with other technologies. Additionally, the software was developed using an SQLite database embedded in the application, ensuring better performance and reliability. It also uses the GoogleMaps library for geolocation of the temporary shelters. This enables searching for any address in the world without compromising the software speed and storage capacity, as it uses the internet to search and load maps.

ShelterPro has six core functionalities to be used: register an event (disaster), register a potential temporary shelter, list events, list the best temporary shelters to a given event, list temporary shelters, and generate reports. The initial screen of the ShelterPro can be visualized in Fig. 5, where the user can find a menu to navigate among the functionalities.

The first core functionality enables the user to register events. To this end, the user needs to enter a name to describe the disaster, the date of occurrence, a radius of coverage, the number of people affected, and an approximate disaster address. In this way, the software stores the registered events in the local database, so the user can retrieve this record at any time in the future. Figure 6 exhibits the screenshot of the user interface for this functionality with the data fields to complete.

For the second core functionality, registration of temporary shelters, the software displays a user interface with data fields to complete, as shown in Fig. 7. First, the user should complete with general information to identify and locate the temporary shelter, e.g., name, address, region, city, and contact. Following this, questions regarding all the 60 performance indicators defined in the multi-criteria model are presented on-screen. The user needs to answer these questions so that the software can collect the necessary information. There are two types of questions: binary questions with "yes" or "no" response (via a dropdown selection) referring to qualitative indicators, and open questions requiring a specific value as an input to the quantitative indicators. 


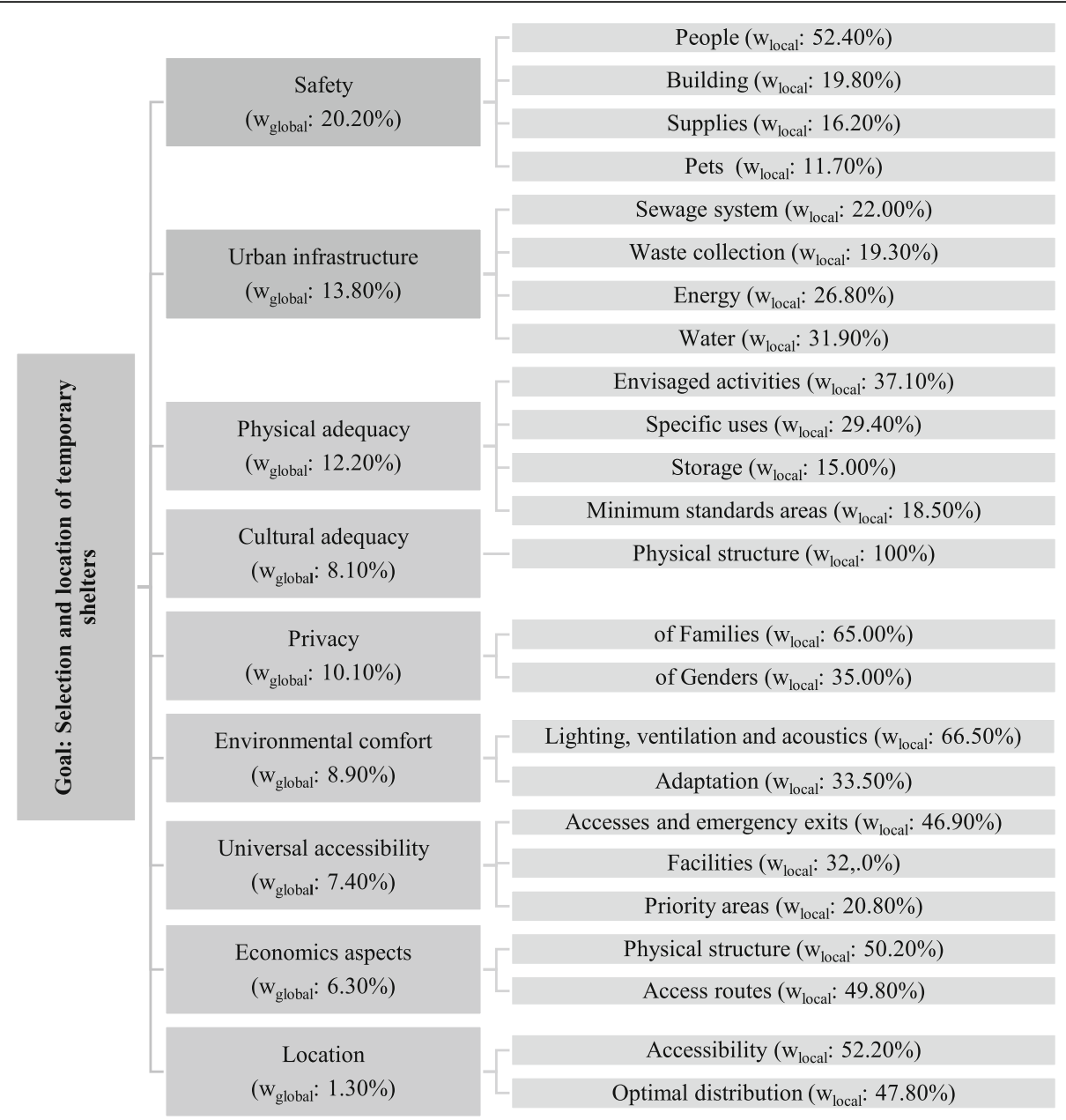

Fig. 3. Final hierarchical tree representation showing the global and local criteria with weights ( $w_{\text {global }}$ : global weight, $W_{\text {local }}$ : local weight)

In total, nine quantitative indicators require the input of a value: volume of water available per day, building total area, kitchen area, number of bathrooms available, number of sinks for possible laundry, area for dormitories, and shelter address. It is important to note that all these parameters are available to the civil defense personnel and local authorities because all potential facilities (schools, multi-sports gyms, public buildings) are registered in the city council they belong to, including the blueprints and technical specifications (SEDEC/RJ 2006).

Although the information needed to register temporary shelters into the database should be available to the civil defense personnel and local authorities, sometimes it might be difficult to obtain them. In such cases, a piece of supporting information is the presence of a usage manual and/or maintenance guidelines for the facility. This is a common practice for public building and schools. This document is particularly interesting for the "Privacy" criteria because it outlines the internal spaces for service areas, kitchen, and dormitories in case of an emergency.
The third core functionality consists of listing the registered events (disasters) in the database, as displayed in Fig. 8. This interface allows the user to visualize the details of all events registered to date and offers the option to edit or delete an event. It also provides access to the fourth core functionality discussed next (via the blue house icon).

The fourth core functionality consists of listing the best temporary shelters for a given event. After selecting the disaster in question, the user clicks on the blue icon mentioned previously requesting the software to generate a ranked list of the registered shelters, starting with the one that best suits the situation and so on. To build this ranking, the software applies an algorithm that follows basic rules to run the calculations of all the 60 indicators resulting in a global value used to rank the best shelters available to be used in a given event.

The first rule refers to the operationalization of qualitative indicators. For the qualitative indicators to which 




the binary answer is "yes," the weight of the indicator is multiplied by one, and the shelter receives the full weight of that specific indicator. In contrast, for those whose binary answer is "no," the weight of the indicator is multiplied by zero, and, therefore, not computed.

The second rule governs the measurement of quantitative indicators. The total weight of the indicator is allocated to all those shelters whose capacity fully meets the minimum requirements dictated by the quantitative indicators according to the population size. For example, the local criterion "Minimum standard areas" is expressed by the indicator "for each person, the total covered area must be at least 4.00 square meters $\left(\mathrm{m}^{2}\right)$ " retrieved from (Sphere Project 2011) (see Appendix, item 3.4). So, in this

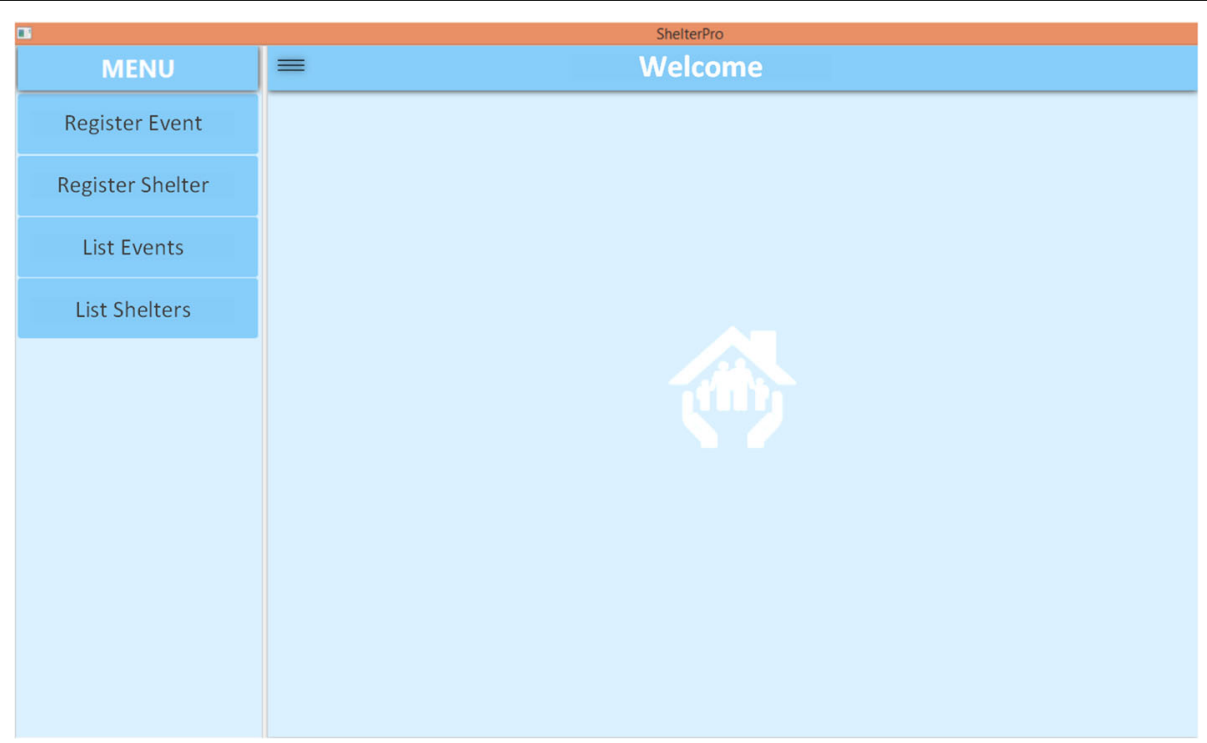

Fig. 5. ShelterPro main menu 


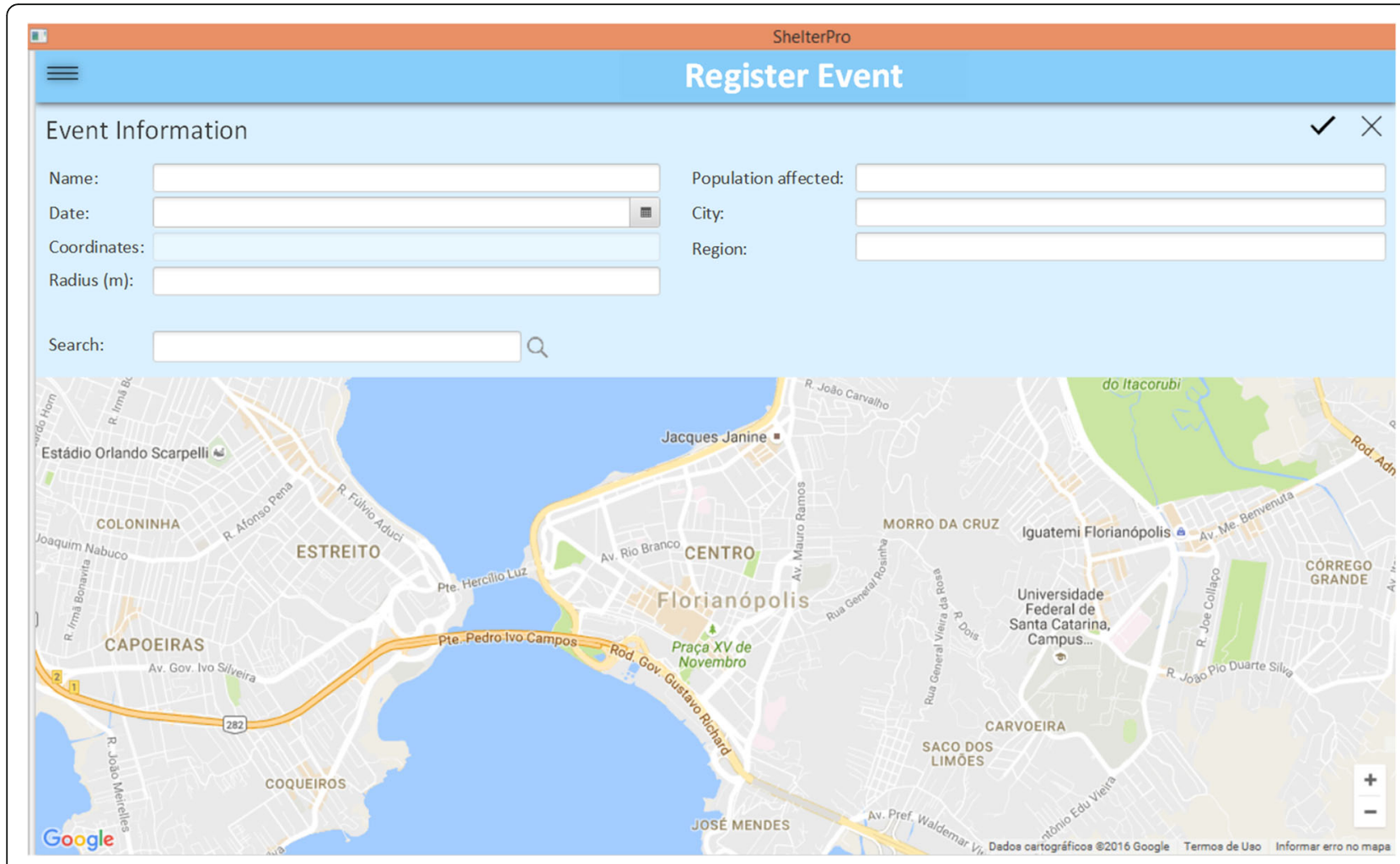

Fig. 6. ShelterPro registration of an event

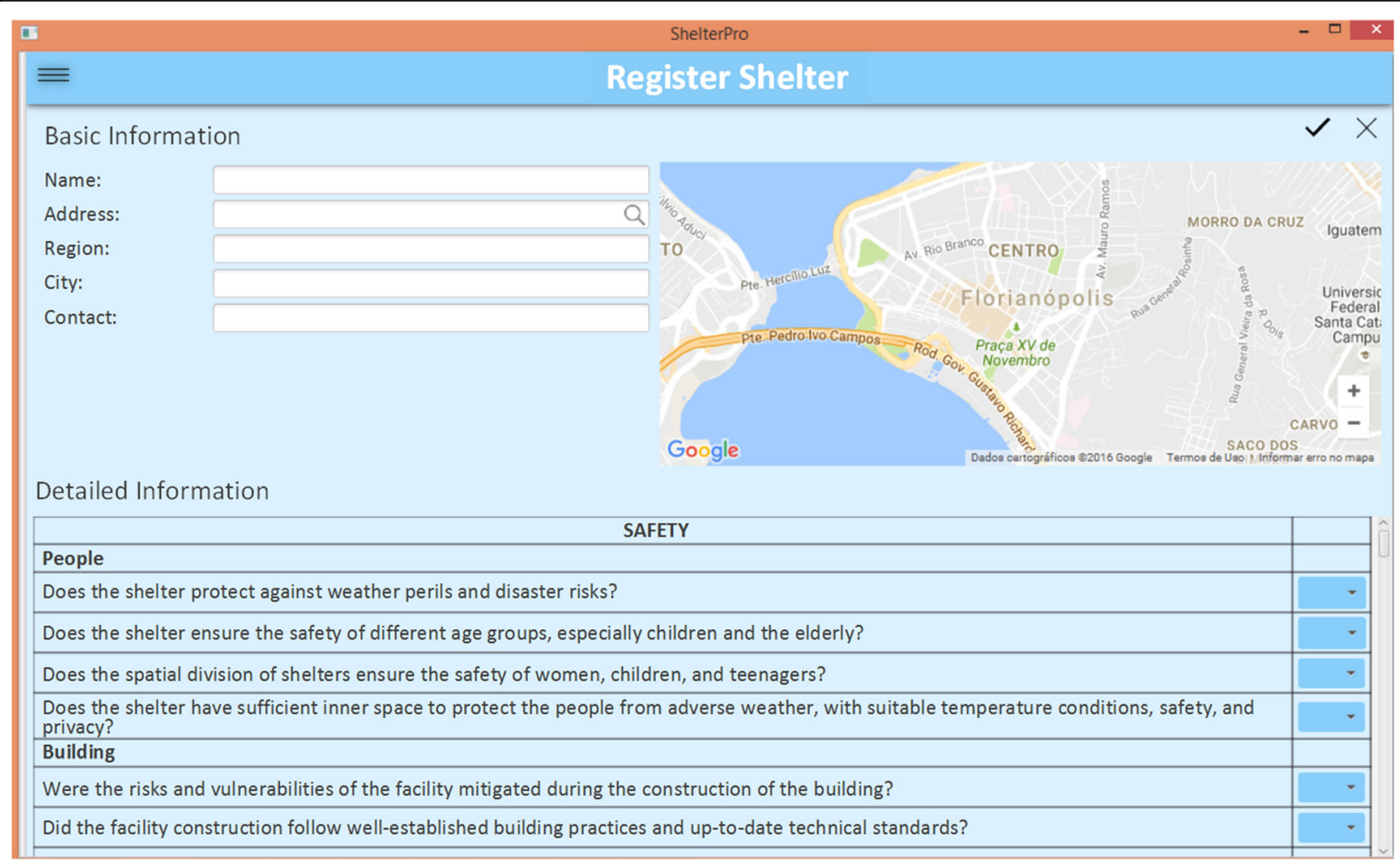

Fig. 7. ShelterPro registration of a temporary shelter 


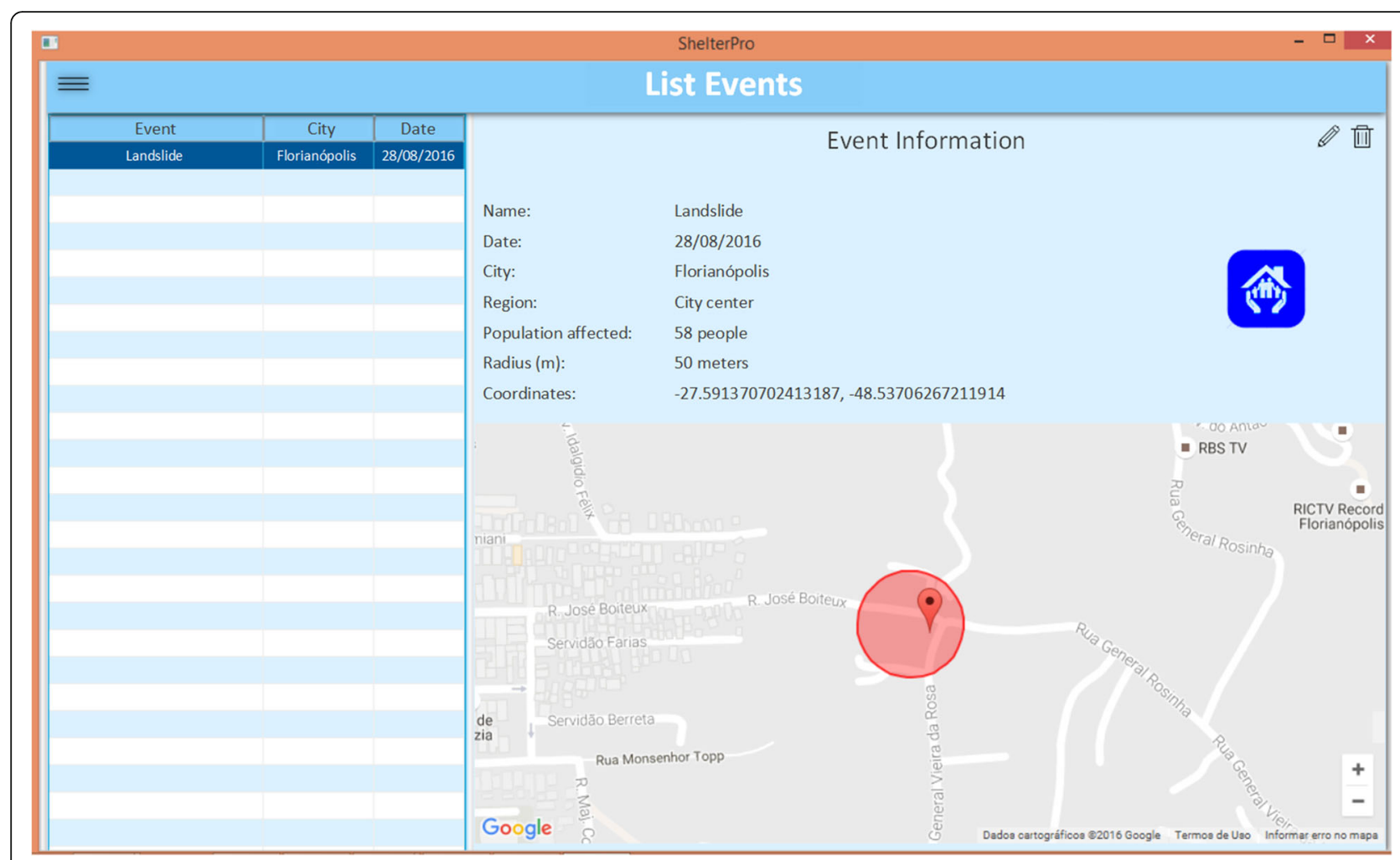

Fig. 8. ShelterPro list of events (with one event as an example)

example, considering a displaced population of 200 people, any shelter that has a covered area of $800 \mathrm{~m}^{2}$ or more will receive the total weight of this indicator (1 multiplying $0.37 \%$ ). For the others, weights are allocated proportionally to their capacity. With the same population size, a shelter with $400 \mathrm{~m}^{2}$ of covered area will be assigned only $50 \%$ of the total weight of this specific indicator because it only presents half of the area needed to host the number of people displaced.

Another example is the local criterion "Privacy of families" which is linked to a performance indicator articulated by the expression "the temporary shelter must have a number of subdivisions (dormitories) compatible with the number of sheltered families" (see Appendix). The user (who is a knowledgeable professional) inputs the area available in square meters of the facility under consideration. At this point, the algorithm divides the total area by the number of displaced families and compares with the minimum area needed to accommodate each family. The number of families at risk is calculated by dividing the number of displaced people by the average size family in the region, provided by the census (known information by the civil defense personnel). The Santa Catarina state, Brazil, has an average family size of 2.9 individuals, so the standard area for dormitories of $2.00 \mathrm{~m}^{2}$ per person (Sphere Project 2011) results in an area of at least $5.80 \mathrm{~m}^{2}$ needed to accommodate each family. Therefore, any temporary shelter that has at least this area available for dormitories will receive the total weight of this indicator $(2.20 \%)$ for the calculation of the global value that is used to build the ranking.

This example also has cultural adequacy considerations. Cultural norms may vary across Brazil, what may be considered essential in one area may not be needed in another. As in some areas, whole families commonly sleep together in one bed or one room, while in others, men and women are separated. In addition to internal civil defense guidelines for these issues according to geographical locations, further relevant information is the availability of internal dividers for the dormitories. These internal dividers can be ready-to-use or built and assembled in situ. Either way, the materials must be culturally adequate. Therefore, they should be locally available rather than purchased from afar. For example, woven bamboo walls are indicated for more isolated areas, whereas acoustical fabric combined with polycarbonate partition wall are more suitable for facilities in gyms or public buildings in large cities. In general, the way to ensure the cultural adequacy and privacy of temporary shelter users is to employ professionals with local experience.

The third rule refers to the aggregation process to achieve the global value for each temporary shelter. 


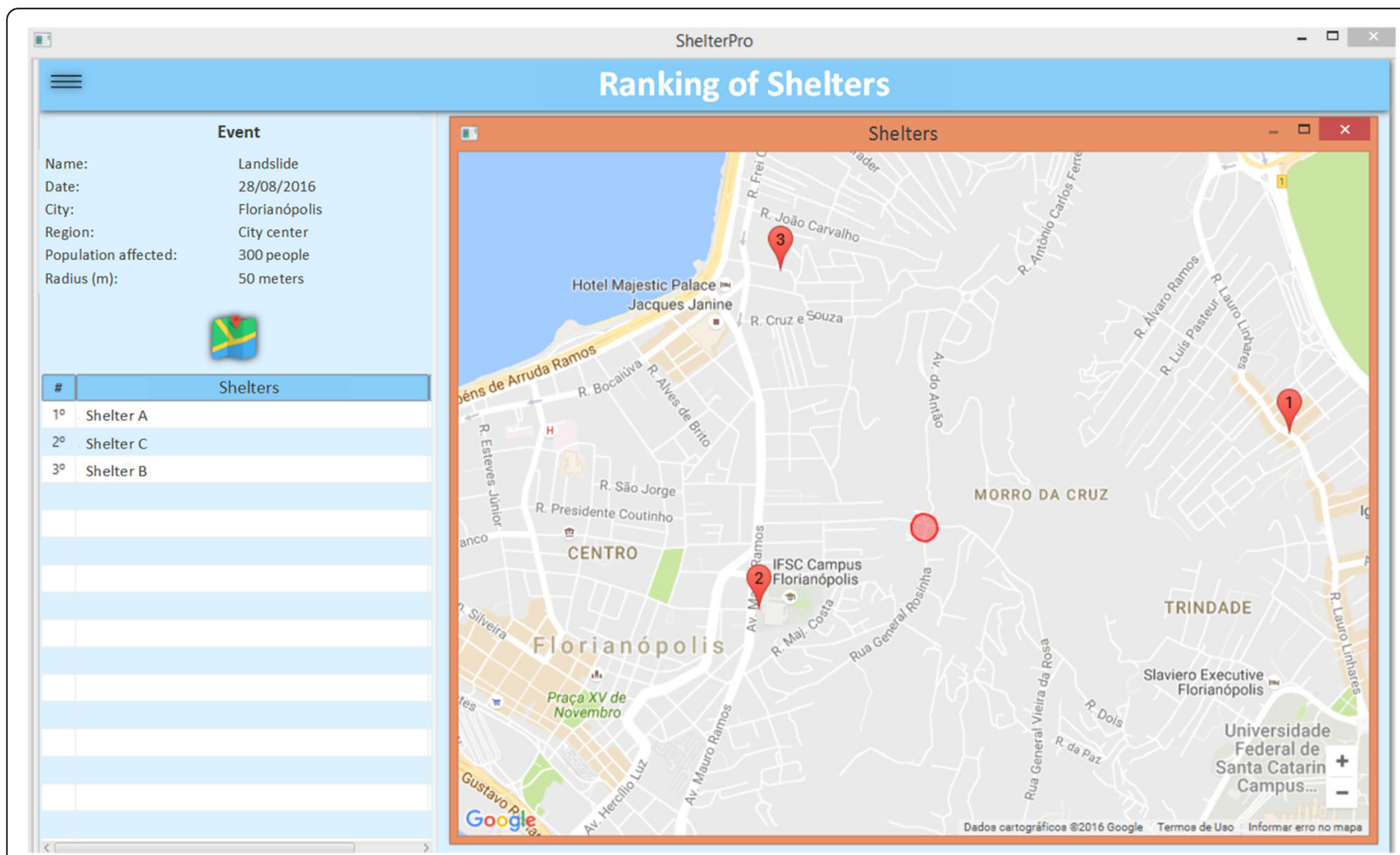

Fig. 9. ShelterPro ranking of best temporary shelters (after selecting an event)

\begin{tabular}{|c|c|c|c|c|}
\hline \multirow[t]{2}{*}{ 四 } & \multicolumn{4}{|c|}{ ShelterPro } \\
\hline & \multicolumn{2}{|l|}{$\equiv$} & List of Shelters & \multirow[b]{2}{*}{ 而 } \\
\hline \multirow{2}{*}{$\operatorname{Reg}$} & \begin{tabular}{|r|r|r} 
& Shelters \\
Shelter A &
\end{tabular} & & \multirow[t]{2}{*}{ Basic Information } & \\
\hline & Shelter $B$ & & & \\
\hline \multirow{2}{*}{$\operatorname{Rec}$} & Shelter C & Name: & Shelter $\mathrm{A}$ & \\
\hline & & Address: & Rua Lauro Linhares & \\
\hline \multirow[t]{2}{*}{ Lis } & & Region: & Trindade & \\
\hline & & City: & Florianópolis & \\
\hline \multirow[t]{12}{*}{ Lis } & & Contact: & (48) 3333-3333 & + \\
\hline & & \multicolumn{3}{|c|}{ Detailed Information } \\
\hline & & \multicolumn{2}{|r|}{ SAFETY } & \\
\hline & & People & & \\
\hline & & Does the & protect against weather perils and disaster risks? & YES \\
\hline & & Does the & ensure the safety of different age groups, especially children and the elderly? & YES \\
\hline & & Does the & division of shelters ensure the safety of women, children, and teenagers? & YES \\
\hline & & $\begin{array}{l}\text { Does the } \\
\text { safety, an }\end{array}$ & $\begin{array}{l}\text { have sufficient inner space to protect the people from adverse weather, with suitable temperature conditions, } \\
\text { cy? }\end{array}$ & YES \\
\hline & & Building & & \\
\hline & & Were the & nd vulnerabilities of the facility mitigated during the construction of the building? & YES \\
\hline & & Did the fa & onstruction follow well-established building practices and up-to-date technical standards? & YES \\
\hline & & Was peric & pection planned to ensure that solutions applied to the temporary shelter continue to be effective over time? & YES \\
\hline
\end{tabular}

Fig. 10. ShelterPro ranked list of temporary shelters (without an event) 
In this sense, the global value is obtained by the sum of each measurement value of the 60 indicators, multiplied by its weight as displayed in the expression:



In this way, ShelterPro ranks the temporary shelters according to their global values, showing the highest value as the best alternative, and working its way down. Therefore, each potential temporary shelter will present a distinct combination of measurements leading to their specific global value due to its particular characteristics. As a proof of concept, currently, there are three examples of temporary shelters in Santa Catarina, as observed in Fig. 9.

These three examples are school's facilities, which are a quite common practice in Latin American and Caribbean countries. The local authorities, in combination with the school's board, coordinate the habilitation process of the school facilities. Existing regulations require schools to have an emergency school plan in place that allows students to attend classes with minimal disruption. The plan contains procedures for the use of the school as a shelter, including the identification of spaces to accommodate utensils, furniture, and school equipment inside the school and gyms to avoid their use or damage by the sheltered population. It also defines the maximum time of use of the school as a temporary shelter and the labeling and identification of service areas, kitchen, common areas, laundries, and so forth. After the habilitation of the school by the local authorities, the civil defense will provide internal dividers such as portable partition walls when needed for the construction of temporary dormitories in gyms or classrooms. The partition walls can also be used to create temporary classrooms in other spaces so that students can attend classes without disturbances caused by the displaced population.

The fifth functionality of the software provides a ranked list showing all the temporary shelters registered in the database without considering an event and also enables the user to edit and delete shelters accordingly (see Fig. 10). To list shelters, the software uses the same algorithm that follows the basic rules to automatically compute a global value used to create a ranking among possible temporary shelters, with one specific variation to run the calculations of the quantitative indicators. These indicators are the ones directly related to the shelter characteristics such as an address, the radius of coverage, and the number of people affected. As there is no input from a disaster, the total weight of the quantitative indicator is attributed solely to the shelter that presents the highest

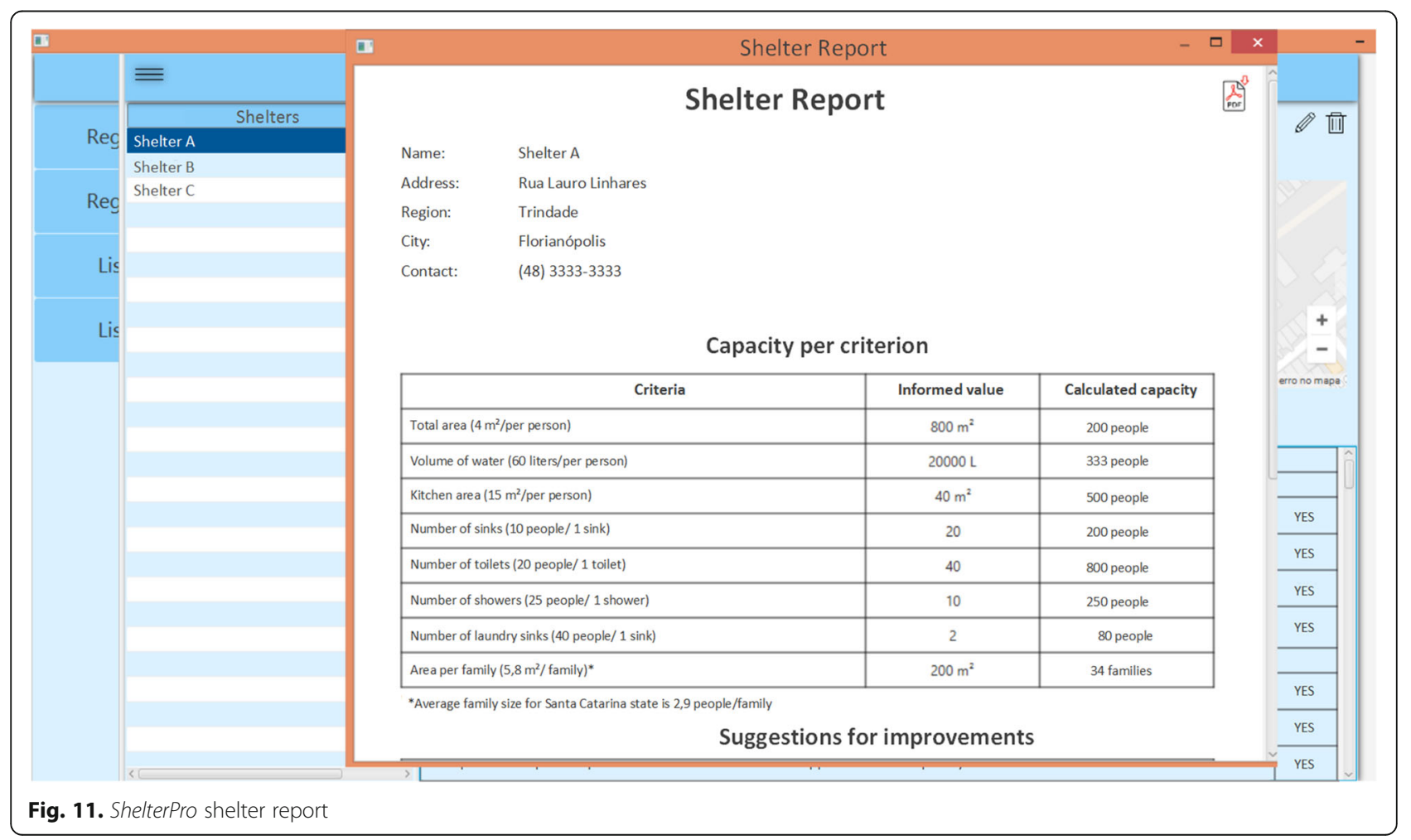


value. In this way, the remaining shelters do not receive the weight of this indicator in question.

Furthermore, users can also obtain a report (in PDF) of a specific temporary shelter showing the capacity per quantitative criterion calculated by the software (see Fig. 11). The report also suggests improvements so that the shelter can be better equipped to accommodate populations at risk. These suggestions are based on the performance of the indicators which did not receive the full weight value. In this way, the users can identify the underperformed standards to be met by the facilities based on requirements validated by experts.

Therefore, considering all the outputs of the six core functionalities, ShelterPro software was developed to be an easy and intuitive decision support tool for humanitarian logistics managers, local authorities, or designated officials. This multi-criteria tool aims to facilitate the work of decision-makers in an emergency, proposing the activation of facilities to function as temporary shelters that are best suited to the situation presented and to the affected population. At the same time, this tool can also support the improvement of existing facilities by demonstrating criteria that need to be observed and improved.

Thus, with the ranking of best shelters in hand, the decision-maker checks the capacity of each potential shelter to identify how many shelters need to be activated based on the number of people affected by the event. Multi-criteria models themselves cannot make the final decisions (Pavan et al. 2009). In this way, the decision-makers are able to prioritize the temporary shelters according to their performance. They should prioritize the shelters that are best positioned in the ranking, and work from topdown until the displaced people are accommodated. In this sense, the proposed model provides support to professionals in making decisions based on qualified information so that they feel comfortable and confident about them.

Finally, this tool has the potential to be transferred to any humanitarian agency. Nevertheless, the validity of research is limited to the studied context of Santa Catarina (Brazil); thus, the results cannot be generalized to all diverse locations. The reason for this is that the weights were assigned by the Civil Defense staff of Santa Catarina, following the literature recommendation of applying local expertise. The model can be extrapolated to a broader context, if the criteria are prioritized by local experts according to the methodology presented here. Thus, we reinforce the importance of developing the weights at the local level and collecting a database of registered temporary shelters in the region.

\section{Concluding remarks}

Planning the response for disaster situations has been recognized as a central challenge in reducing the impact of such events around the world (Kunz et al., 2014). Research is increasingly addressing this problem in order to improve aid assistance and its effectiveness (Kovács and Spens 2007; Kovács and Tatham 2009; Vitoriano et al. 2011; Gralla et al. 2014; Chandes and Paché 2010). In this context, organizations in the humanitarian aid sector are beginning to acknowledge the importance of multi-criteria decision models for improving their operations and management of disasters, including the selection of temporary shelters. Nevertheless, academic research does not provide decision support models and tools for this purpose.

The objective of this study was to propose a unique multi-criteria decision model for the selection and location of temporary shelters to support managers of humanitarian aid organizations in their decision-making process. The first contribution is the compilation of 24 local criteria to assess temporary shelters using a systematic literature review that also allowed the gathering of 60 performance indicators. Thus, this comprehensive collection not only provides options to humanitarian logistics managers to analyze possible shelters, even without the use of the model, but also a base for researchers to build up new studies. The second contribution refers to the resulting model, operationalized in the form of the software ShelterPro as a proof of concept, which supports both the strategic and operational level of humanitarian logistics decisions.

At the strategic level, the model allows the collection of a diverse range of facilities to function as temporary shelters and the prioritization of best alternatives in the case of a disaster. Furthermore, this model can also indicate to policy-makers and technical specialists (architects/engineers) the need for new shelter structures as well as modifications and adaptations in existing ones. At the operational level, the multi-criteria decision tool helps civil defense professionals in the selection and location of the registered temporary shelters to accommodate the affected population, enabling a faster response to emergency situations in the context of Santa Catarina, Brazil.

Future work should apply this proposed multi-criteria decision model in other national and international contexts to compare the results and to build local databases of temporary shelters across a range of regions. In addition, the software developed could be further enhanced to include optimization strategies and algorithms to improve the distribution and transportation of the affected population. 


\section{Appendix}

Table 2 Description of global criteria (G) and local criteria (L)

\begin{tabular}{|c|c|c|c|c|}
\hline \multirow{2}{*}{\multicolumn{2}{|c|}{ Description }} & \multirow{2}{*}{\multicolumn{3}{|c|}{ Weight (w) }} \\
\hline & & & & \\
\hline 1 & Safety $(G)$ & \multicolumn{2}{|c|}{\begin{tabular}{l|l}
$W_{\text {global }}$ \\
$20.20 \%$
\end{tabular}} & Wlocal \\
\hline \multirow[t]{5}{*}{1.1} & People (L) & & & $10.60 \%$ \\
\hline & The shelter should safeguard and protect against weather perils and further disaster risks. & Yes & No & $2.65 \%$ \\
\hline & The shelter should ensure the safety of different age groups, especially children and the elderly. & Yes & No & $2.65 \%$ \\
\hline & The spatial division of shelters must ensure the safety of women, children, and teenagers. & Yes & No & $2.65 \%$ \\
\hline & $\begin{array}{l}\text { The users must have access to sufficient inner space in the shelter in order to protect themselves } \\
\text { from adverse weather, with suitable temperature conditions, safety, and privacy. }\end{array}$ & Yes & No & $2.65 \%$ \\
\hline \multirow[t]{6}{*}{1.2} & Building $(L)$ & & & $4.00 \%$ \\
\hline & $\begin{array}{l}\text { During the construction of the building (used as temporary shelter), risks and vulnerabilities that } \\
\text { could prevent its use should have been detected and mitigated. }\end{array}$ & Yes & No & $0.80 \%$ \\
\hline & $\begin{array}{l}\text { The building (used as a temporary shelter) must be constructed following well-established building } \\
\text { practices and up-to-date technical standards. }\end{array}$ & Yes & No & $0.80 \%$ \\
\hline & $\begin{array}{l}\text { The planning of periodic inspections must ensure that the solutions applied to the temporary shelter } \\
\text { continue to be effective over time. }\end{array}$ & Yes & No & $0.80 \%$ \\
\hline & $\begin{array}{l}\text { The temporary shelter should be located at a reasonable distance from the danger zone in order to } \\
\text { minimize the risks. }\end{array}$ & Yes & No & $0.80 \%$ \\
\hline & The building must be equipped with a working firefighting system. & Yes & No & $0.80 \%$ \\
\hline \multirow[t]{2}{*}{1.3} & Supplies (L) & & & $3.30 \%$ \\
\hline & The temporary shelter must have a secure storage area for supplies. & Yes & No & $3.30 \%$ \\
\hline \multirow[t]{2}{*}{1.4} & Pets $(L)$ & $2.40 \%$ & & \\
\hline & The temporary shelter should have an area for pets' caretaking. & Yes & No & $2.40 \%$ \\
\hline 2 & Urban infrastructure (G) & 13.809 & & \\
\hline \multirow[t]{2}{*}{2.} & Swage system (L) & & & $3.00 \%$ \\
\hline & The building must be in a place where there is a sewage collection system or equivalent. & Yes & No & $3.00 \%$ \\
\hline \multirow[t]{2}{*}{2.2} & Waste collection (L) & & & $2.70 \%$ \\
\hline & The temporary shelter should be in a place within reach of waste management companies. & Yes & No & $2.70 \%$ \\
\hline \multirow[t]{3}{*}{2.3} & Energy (L) & & & $3.70 \%$ \\
\hline & The temporary shelter must be in a place with access to electricity. & Yes & No & $1.85 \%$ \\
\hline & The shelter must be equipped with a generator for backup power supply. & Yes & No & $1.85 \%$ \\
\hline \multirow[t]{4}{*}{2.4} & Water (L) & & & $4.40 \%$ \\
\hline & $\begin{array}{l}\text { The temporary shelter must be in a place where there is regular water supply or easy access for } \\
\text { water trucks and tankers. }\end{array}$ & Yes & No & $1.47 \%$ \\
\hline & The volume of water available per day should meet the estimated 2.5 liters of drinking per person. & Yes & No & $1.47 \%$ \\
\hline & $\begin{array}{l}\text { The volume of water available in the shelter per day should meet the estimated } 60 \text { liters per bath } \\
\text { per person. }\end{array}$ & Value & & $1.47 \%$ \\
\hline 3 & Physical adequacy (G) & 12.209 & & \\
\hline \multirow[t]{6}{*}{3.1} & Envisaged activities (L) & & & $4.50 \%$ \\
\hline & $\begin{array}{l}\text { In the temporary shelter, the internal spaces should provide enough space to store food, water, } \\
\text { personal belongings, and other essential items. }\end{array}$ & Yes & No & $0.90 \%$ \\
\hline & Every family should have a safe and private interior space, like dormitories. & Yes & No & $0.90 \%$ \\
\hline & $\begin{array}{l}\text { In the temporary shelter, interior spaces should offer enough space for the activities of sleeping, } \\
\text { bathing, and dressing. }\end{array}$ & Yes & No & $0.90 \%$ \\
\hline & In the temporary shelter, interior spaces should offer enough space for caring for infants and children. & Yes & No & $0.90 \%$ \\
\hline & In the temporary shelter, interior spaces should offer enough space for the coexistence of members & Yes & No & $0.90 \%$ \\
\hline
\end{tabular}


Table 2 Description of global criteria (G) and local criteria (L) (Continued)

\begin{tabular}{|c|c|c|c|c|}
\hline \multicolumn{2}{|c|}{ Description } & \multicolumn{3}{|c|}{ Weight (w) } \\
\hline & & \multirow{2}{*}{\multicolumn{2}{|c|}{$W_{\text {global }}$}} & \multirow{2}{*}{$\frac{W_{\text {local }}}{3.60 \%}$} \\
\hline 3.2 & Specific uses (L) & & & \\
\hline & The building should allow the establishment of a kitchen. & Yes & No & $0.60 \%$ \\
\hline & The building should provide the establishment of a canteen. & Yes & No & $0.60 \%$ \\
\hline & The building should allow the establishment of living areas. & Yes & No & $0.60 \%$ \\
\hline & The building should allow the establishment of dormitories. & Yes & No & $0.60 \%$ \\
\hline & The building should have both men's and women's toilets. & Yes & No & $0.60 \%$ \\
\hline & The building should enable the creation of spaces for medical and psychological care. & Yes & No & $0.60 \%$ \\
\hline \multirow[t]{4}{*}{3.3} & Storage $(\mathrm{L})$ & & & $1.80 \%$ \\
\hline & $\begin{array}{l}\text { The building should allow the establishment of space to stock possible movable items } \\
\text { of the affected population salvaged from their households. }\end{array}$ & Yes & No & $0.60 \%$ \\
\hline & $\begin{array}{l}\text { The building should allow the establishment of space for the shelter of pets belonging } \\
\text { to the sheltered families. }\end{array}$ & Yes & No & $0.60 \%$ \\
\hline & $\begin{array}{l}\text { The building should allow the establishment of a place reserved for waste collection by } \\
\text { the responsible company. }\end{array}$ & Yes & No & $0.60 \%$ \\
\hline \multirow[t]{7}{*}{3.4} & Minimum standards areas $(\mathrm{L})$ & & & $2.20 \%$ \\
\hline & For each person, the total covered area must be at least $4.00 \mathrm{~m}^{2}$. & Value & & $0.37 \%$ \\
\hline & $\begin{array}{l}\text { The kitchen must have a minimum area of } 15.00 \mathrm{~m}^{2} \text { for each industrial six-burner stove, } \\
\text { which serves up to } 250 \text { people. }\end{array}$ & Value & & $0.37 \%$ \\
\hline & The bathrooms must have at least one lavatory for every 10 people. & Value & & $0.37 \%$ \\
\hline & The bathrooms must have at least one toilet for every 20 people. & Value & & $0.37 \%$ \\
\hline & The bathrooms must have at least one shower for every 25 people. & Value & & $0.37 \%$ \\
\hline & The laundry/service area should have one laundry sink for every 40 people. & Value & & $0.37 \%$ \\
\hline \multirow[t]{3}{*}{4} & Cultural adequacy (G) & $8.10 \%$ & & \\
\hline & Physical structure (L) & $8.10 \%$ & & \\
\hline & $\begin{array}{l}\text { The construction of the building (to be used as a temporary shelter) should be assigned } \\
\text { to professionals with expertise in local solutions. }\end{array}$ & Yes & No & $8.10 \%$ \\
\hline 5 & Privacy (G) & $10.10^{\circ}$ & & \\
\hline \multirow[t]{4}{*}{5.1} & of Families (L) & & & $6.60 \%$ \\
\hline & $\begin{array}{l}\text { The building should ensure privacy and dignity to the people affected, even if it needs } \\
\text { adaptations of the internal space. }\end{array}$ & Yes & No & $2.20 \%$ \\
\hline & The temporary shelter must have spatial division designed to preserve family cohesion. & Yes & No & $2.20 \%$ \\
\hline & $\begin{array}{l}\text { The temporary shelter must have a number of subdivisions (dormitories) compatible with } \\
\text { the number of sheltered families. }\end{array}$ & Value & & $2.20 \%$ \\
\hline \multirow[t]{2}{*}{5.2} & of Genders (L) & & & $3.50 \%$ \\
\hline & The temporary shelter must provide safe separation and privacy between genders. & Yes & No & $3.50 \%$ \\
\hline 6 & Environmental comfort (G) & $8.90 \%$ & & \\
\hline \multirow[t]{4}{*}{6.1} & Lighting, ventilation, and acoustics (L) & & & $5.90 \%$ \\
\hline & $\begin{array}{l}\text { The specific weather conditions for each season should be evaluated so that the shelter } \\
\text { can provide thermal comfort, ventilation, and protection to the affected population. }\end{array}$ & Yes & No & $1.97 \%$ \\
\hline & The shelter should optimize natural ventilation and minimize direct sun exposure. & Yes & No & $1.97 \%$ \\
\hline & $\begin{array}{l}\text { Trees or other types of vegetation should be preserved whenever possible in order to increase } \\
\text { water retention, minimize soil erosion and to provide shade. }\end{array}$ & Yes & No & $1.97 \%$ \\
\hline \multirow[t]{2}{*}{6.2} & Adaptation (L) & & & $3.00 \%$ \\
\hline & The place used for shelter should be adaptable to weather and temperature variations. & Yes & No & $3.00 \%$ \\
\hline 7 & Universal accessibility (G) & $7.40 \%$ & & \\
\hline 7.1 & Accesses and emergency exits (L) & & & $3.50 \%$ \\
\hline
\end{tabular}


Table 2 Description of global criteria (G) and local criteria ( $L$ ) (Continued)

\begin{tabular}{|c|c|c|c|c|}
\hline \multirow{2}{*}{\multicolumn{2}{|c|}{ Description }} & \multicolumn{3}{|c|}{ Weight (w) } \\
\hline & & & & \\
\hline & $\begin{array}{l}\text { The building should be of easy access and evacuation, without steps or uneven surfaces in the } \\
\text { emergency exits. }\end{array}$ & Yes & No & $\frac{W_{\text {local }}}{3.50 \%}$ \\
\hline \multirow[t]{4}{*}{7.2} & Facilities (L) & & & $2.40 \%$ \\
\hline & $\begin{array}{l}\text { The location of the temporary shelter must comply with the standards and procedures } \\
\text { for building approval, especially accessibility requirements for people with reduced } \\
\text { mobility, vision or communication skills. }\end{array}$ & Yes & No & $0.80 \%$ \\
\hline & The building must have bathrooms adapted for people with physical disabilities. & Yes & No & $0.80 \%$ \\
\hline & The building must have dormitories adapted for people with physical disabilities. & Yes & No & $0.80 \%$ \\
\hline \multirow[t]{2}{*}{7.3} & Priority areas $(L)$ & & & $1.50 \%$ \\
\hline & $\begin{array}{l}\text { For families with seniors and people with physical disabilities, the building should allow } \\
\text { the creation of reserved spaces in places easily accessible to bathrooms, to the food } \\
\text { sector, among others. }\end{array}$ & Yes & No & $1.50 \%$ \\
\hline 8 & Economic aspects $(G)$ & $6.30 \%$ & & \\
\hline \multirow[t]{4}{*}{8.1} & Physical structure (L) & & & $3.20 \%$ \\
\hline & $\begin{array}{l}\text { The facility (to be used as a temporary shelter) should be developed in consultation with } \\
\text { the competent authorities and grounded in a consensual strategy for services and } \\
\text { maintenance at an affordable cost. }\end{array}$ & Yes & No & $1.07 \%$ \\
\hline & $\begin{array}{l}\text { The facility (to be used as a temporary shelter) should allow other uses, for example, } \\
\text { community centers, avoiding underutilization of the structure. }\end{array}$ & Yes & No & $1.07 \%$ \\
\hline & $\begin{array}{l}\text { The selection of the temporary shelter should aim to minimize expenses on improvements } \\
\text { and adaptations. }\end{array}$ & Yes & No & $1.07 \%$ \\
\hline \multirow[t]{2}{*}{8.2} & Access to the provisions $(\mathrm{L})$ & & & $3.10 \%$ \\
\hline & $\begin{array}{l}\text { The location of the building should allow easy access to workplaces and other means of } \\
\text { subsistence for the affected population. }\end{array}$ & Yes & No & $3.10 \%$ \\
\hline 9 & Location (G) & 13.00 & & \\
\hline \multirow[t]{2}{*}{9.1} & Accessibility (L) & & & $6.80 \%$ \\
\hline & $\begin{array}{l}\text { The location of the building should provide safe access to schools, markets, leisure spaces, } \\
\text { worship places, health clinics and hospitals, and other services necessary for the day-to-day } \\
\text { lives of the affected population. }\end{array}$ & Yes & No & $6.80 \%$ \\
\hline \multirow[t]{4}{*}{9.2} & Optimal distribution (L) & & & $6.20 \%$ \\
\hline & $\begin{array}{l}\text { Maximum distance to be covered by the population at risk to the building (inform the } \\
\text { position on the map). }\end{array}$ & Map & & $2.07 \%$ \\
\hline & $\begin{array}{l}\text { The selection of the facility should consider the maximum time of arrival of humanitarian } \\
\text { aid supplies to the building. }\end{array}$ & Yes & No & $2.07 \%$ \\
\hline & The access routes for the population at risk should be pre-determined. & Yes & No & $2.07 \%$ \\
\hline
\end{tabular}

\section{Abbreviations}

AHP: Analytic hierarchic process; CAPES: Coordenação de Aperfeiçoamento de Pessoal de Nível Superior; SEDEC/RJ: Secretaria de Estado da Defesa Civil do Rio de Janeiro; UN: United Nations; UNICEF: United Nations Children's Fund

\section{Acknowledgments}

The authors would like to thank the Post-Graduation Program in Architecture and Urbanism (PósARQ) of Universidade Federal de Santa Catarina (UFSC) and the Coordenação de Aperfeiçoamento de Pessoal de Nível Superior (CAPES).

\section{Authors' contributions}

All authors read and approved the final manuscript.

\section{Funding}

This study was financed in part by the Coordenação de Aperfeiçoamento de Pessoal de Nível Superior-Brasil (CAPES)_Finance Code 001.

\section{Availability of data and materials}

The datasets used and/or analyzed during the current study are available from the corresponding author on reasonable request.

\section{Competing interests}

The authors declare that they have no competing interests.

\section{Author details}

${ }^{1}$ Universidade Federal de Santa Catarina (UFSC), Campus Universitário Reitor João David Ferreira Lima - Trindade, Florianópolis, SC 88040-900, Brazil.

${ }^{2}$ Trinity College Dublin, the University of Dublin, College Green, Dublin, Ireland.

Received: 8 February 2019 Accepted: 30 July 2019

Published online: 06 September 2019

\section{References}

Apte A (2009) Humanitarian logistics: a new field of research and action. Foundations and Trends ${ }^{\oplus}$ in Technology, Information and Operations Management 3(1):1-100. https://doi.org/10.1561/0200000014 
Argüello-Rodríguez M (2004) Riesgo, vivienda y arquitectura. Congreso Arqsur, Universidad de San Juan, Argentina, San Juan, p 2004

Avila Mogollon RM (2000) El AHP y su aplicación para determinar los usos de tierras. El caso de Brasil, Proyecto Regional Información sobre tierras y aguas para un desarrollo agrícola sostenible (Proyecto GCP/RLA/126/JPN). In: Food and Agriculture Organization (FAO) of the United Nations http://www.fao. org/tempref/Gl/Reserved/FTP_FaoRlc/old/proyecto/139jpn/document/3 dctos/sirtplan/infotec/2ahptx.pdf. Accessed 14 Mar 2019

Beamon BM (2008) Performance measurement in humanitarian relief chains. International Journal of Public Sector Management 21(1):4-25. https://doi. org/10.1108/09513550810846087

Chandes J, Paché G (2010) Investigating humanitarian logistics issues: from operations management to strategic action. J Manuf Technol Manag 21(3): 320-340. https://doi.org/10.1108/17410381011024313

Chou T-Y, Hsu C-L, Chen M-C (2008) A fuzzy multi-criteria decision model for international tourist hotels location selection. International Journal of Hospitality Management 27(2):293-301. https://doi.org/10.1016/j.jihm.2007.07.029

Costa FG, Flauzino RF, Navarro MBMA, Cardoso TAO (2017) Abrigos temporários em desastres: a experiência de São José do Vale do Rio Preto, Brasil. Saúde em Debate 41:327-337. https://doi.org/10.1590/0103-11042017S227

GFDRR (Global Facility for Disaster Reduction and Recovery) (2014) Understanding risk in an evolving world: emerging best practices in natural disaster risk assessment. World Bank and GFDRR

Gralla E, Goentzel J, Fine C (2014) Assessing trade-offs among multiple objectives of humanitarian aid delivery using expert preferences. Production and Operations Management 23(6):978-989. https://doi.org/10.1111/poms.12110

Hosseini S, De La Fuente A, Pons O (2016) Multicriteria decision-making method for sustainable site location of post-disaster temporary housing in urban areas. Journal of Construction Engineering and Management 142(9): 04016036. https://doi.org/10.1061/(ASCE)CO.1943-7862.0001137

Kar B, Hodgson ME (2008) A GIS-based model to determine site suitability of emergency evacuation shelters. Transactions in GIS 12(2):227-248. https://doi. org/10.1111/j.1467-9671.2008.01097.x

Kovács G, Spens KM (2007) Humanitarian logistics in disaster relief operations. International Journal of Physical Distribution \& Logistics Management 37(2): 99-114. https://doi.org/10.1108/09600030710734820

Kovács GE, Tatham P (2009) Humanitarian logistics performance in the light of gender. International Journal of Productivity and Performance Management 58(2):174-187. https://doi.org/10.1108/17410400910928752

Kunz N, Reiner G, Gold S (2014) Investing in disaster management capabilities versus pre-positioning inventory: a new approach to disaster preparedness. Int. J. Prod. Econ. 157:261-272. https://doi.org/10.1016/j.ijpe.2013.11.002

Marino P, Muñoz de Cuerva F, Ceano-Vivas M (2016) Emergency housing planning during natural disasters. Earthquakes in Haiti and Spain. Revista INVI 31(87):115-141. https://doi.org/10.4067/invi.v0i0.1000

Matos DAS (2014) Confiabilidade e concordância entre juízes: aplicações na área educacional. Estudos em Avaliação Educacional 25(59):298-324. https://doi. org/10.18222/eae255920142750

Nappi MML, Souza JC (2014) Logística Humanitaria: Indicadores de Sostenibilidad para Alojamientos Temporales. Noticreto 122:12-15

Nappi MML, Souza JC (2015) Disaster management: hierarchical structuring criteria for selection and location of temporary shelters. Nat Hazards 75 : 2421-2436. https://doi.org/10.1007/s11069-014-1437-4

Omidvar B, Baradran-Shoraka M, Nojavan M (2013) Temporary site selection and decision-making methods: a case study of Tehran, Iran. Disasters 37(3):536553. https://doi.org/10.1111/disa.12007

Pavan M, Todeschini R, Chemometrics C (2009) Multi-criteria decision making learn more about multi-criteria decision making multicriteria decision-making methods

Poister TH (2003) Measuring performance in public and nonprofit organizations. Jossey-Bass, San Francisco

Power DJ (2000) Decision Support Systems Hyperbook. Cedar Falls, IA: DSSResources.COM, HTML version. http://dssresources.com/dssbook/. Accessed 26 Dec 2015

Rolnik R (2011) Report of the special rapporteur on adequate housing as a component of the right to an adequate standard of living (A/66/270). In: United Nations Digital Library https://digitallibrary.un.org/record/710032/files/ A_66_270-EN.pdf. Accessed 21 Feb 2018

Saaty TL (1990) How to make a decision: the analytic hierarchy process. European Journal of Operational Research 48(1):9-26. https://doi.org/10.1016/0377-221 7(90)90057-1
Saaty TL (1991) Método de análise hierárquica. Tradução e revisão técnica Wainer da Silveira e Silva. São Paulo, McGraw-Hill Pub, Makron

SEDEC/RJ - Secretaria de Estado da Defesa Civil do Rio de Janeiro (2006) Administração para abrigos temporários. 1. ed. Rio de Janeiro: SEDEC-RJ. http://www.defesacivil.rj.gov.br/images/sedec-arquivos/manual_abrigo_ sedec_rj.pdf

Sphere Project Proyecto Esfera EL (2011) Humanitarian charter and minimum standards in humanitarian, 3a edn. Belmont Press Ltd, Northampton

Stemler SE (2004) A comparison of consensus, consistency, and measurement approaches to estimating interrater reliability. Practical Assessment, Research \& Evaluation 9(4):1-11

Subramoniam R, Huisingh D, Babu R, Subramoniam S (2013) Remanufacturing decision-making framework (RDMF): research validation using the analytical hierarchical process. Journal of Cleaner Production 40:212-220. https://doi. org/10.1016/j.jclepro.2011.09.004

Trivedi A, Singh A (2017) A hybrid multi-objective decision model for emergency shelter location-relocation projects using fuzzy analytic hierarchy process and goal programming approach. International Journal of Project Management 35(5):827-840. https://doi.org/10.1016/j.ijproman.2016.12.004

UN General Assembly (1948) Universal declaration of human rights (217 [III] A), Paris https://www.un.org/en/universal-declaration-human-rights/. Accessed 8 May 2019

UNICEF (2008) Albergues en escuela, cuándo?, cómo/, por qué? In: United Nations Office for Disaster Risk Reduction (UNISDR). http://www.eird.org/cd/ toolkit08/material/Inicio/escuela_albergue/escuela-albergue.pdf. Accessed 20 Feb 2019

Vitoriano B, Ortuño MT, Tirado G, Montero J (2011) A multi-criteria optimization model for humanitarian aid distribution. Journal of Global Optimization 51(2): 189-208. https://doi.org/10.1007/s10898-010-9603-z

\section{Publisher's Note}

Springer Nature remains neutral with regard to jurisdictional claims in published maps and institutional affiliations.

\section{Submit your manuscript to a SpringerOpen ${ }^{\circ}$ journal and benefit from:}

- Convenient online submission

- Rigorous peer review

- Open access: articles freely available online

High visibility within the field

- Retaining the copyright to your article

Submit your next manuscript at $\boldsymbol{\sim}$ springeropen.com 